\title{
Exercising to enhance the efficacy of COVID-19 vaccines
}

\section{Qais Gasibat ${ }^{\text {a }}$}

a, PT, BSc, MSc, Lecturer at Faculty of Medical Technology, Misurata, Libya and PhD Student at University Putra, Malaysia (UPM)

\section{Introduction}

Vaccination is the best and the most costeffective strategy for tackling infectious diseases and their complications. ${ }^{1}$ A successful vaccine elicits a strong and durable immune response in the body to protect against illness.

According to The U.S. Food and Drug Administration (2020), any candidate for a Severe Acute Respiratory Syndrome Coronavirus 2 (SARSCoV-2) vaccine will be approved if it decreases Coronavirus-19 Disease (COVID-19) cases by at least $50 \%$ in comparison to placebo (i.e., $50 \%$ efficacy). Based on the preliminary reports, the efficacy level of Pfizer- BioNTech and Moderna vaccines are $\sim 95 \% .^{2}$ The speed with which these vaccines have been developed is highly impressive. ${ }^{3}$ Vaccine development is dependent on various factors related to the nature of the vaccine, but also characteristics of vaccine recipients and people at risk of illness. Stress, rampant during the pandemic, can not only reduce vaccine efficacy but also promote more immediate and transient side effects, such as fatigue and low mood. However, many of these factors are modifiable and thus may be important intervention targets as the world prepares for widespread immunization.

\section{Exercise and Immunogenicity}

Physical activity promotes a strong immune system and better vaccine responses. Physically fit elderly people had better antibody immune responses, but not cell-mediated immune responses, to tetanus and influenza virus vaccines compared with their less-fit peers. ${ }^{4}$ Accelerometer data was collected from elderly Chinese women in Singapore. It showed that women who walked more $(>18,509$ steps/day) for two weeks after an influenza virus vaccination possessed greater innate immune activation two days after vaccination, larger adaptive immune responses 1 week after vaccination, and greater antibody responses after a second vaccination than their less-active peers $(<10,927$ steps per day). ${ }^{5}$

In another study, it was observed that elite athletes possessed specifically more immune cells for influenza after receiving an influenza vaccine in comparison to other adults who were healthy. ${ }^{6}$ In another study, it was observed that adults who were regular trainers possessed an increased antibody response compared to healthy adults who did not train well. ${ }^{7}$ If constant exercise is done after vaccination, then it is considered to prolong increased protection.

Researchers found that "acute bouts" of exercise, such as work outs prior to vaccination, can accelerate better function of the immune system. ${ }^{8} \mathrm{~A}$ systematic review of 20 studies showed that regular exercise and vaccination are important factors in developing the body's response towards vaccines. ${ }^{9}$

Exercising on the day of the vaccine may offer benefits as well, though there is not much proof. ${ }^{10}$ Eccentric exercise shows benefits to vaccine response. It increases the antibody responses in women and enhances the cell-mediated response in men. Further exploration is needed to study the eccentric exercise of the muscle at the site of vaccine 
administration as a possible behavioral adjuvant to vaccination. ${ }^{11}$

Several studies in young healthy adults show that acute exercise can boost both antibody and cellmediated responses to vaccine antigens. ${ }^{12}$ Exerciseinduced enhancement appears to be most visible in strains with weaker control responses, indicating a possible ceiling effect with stronger responses showing no further enhancement. ${ }^{13}$ During six months of follow-up, acute exercise reduced vaccine reactions but had no effect on either antibody responses or the development of influenza-like symptoms. Being active close to the time of a vaccination - such as influenza or human papillomavirus (HPV), has been found to reduce the risk of suffering from adverse reactions to the injection. ${ }^{14}$

Edwards et al. observed the greater immune response to low-dose pneumococcal vaccine in those who exercised simply with 15 minutes of moderate resistance band exercise; the exercise task was performed in sets of 30 seconds of exercise followed by 30 seconds of rest. ${ }^{15}$ Participants performed three exercises in a row: lateral raise, upright row, and chest press. Each movement was performed with instruction and encouragement to perform "as many as you can." Participants alternated movements and performed each 5 times, completing 15 minutes of exercise. Resistance band strength was adjusted to remain challenging while still allowing for 30 seconds of exercise.

\section{Exercise for COVID-19 Vaccines}

According to a February Lancet study, people who engage in "moderate-intensity exercise before vaccination" have higher rates of efficacy and more antibodies to COVID-19 vaccines. However, the evidence was never fully conclusive because other studies found no discernible difference. ${ }^{16}$

Exercise as an adjuvant provides an avenue that could potentially improve the protective efficacy of vaccination programs in at-risk, immunecompromised populations or even provide a route for dose sparing or a reduction in booster requirement.
Critically, this behavioral approach avoids costly clinical trials, is inexpensive and simple to administer, is well understood and accepted by the general public, and has no side effects other than mild muscle soreness. Of course, correlation between exercise capacity and immune function could be due to pre-existing health status. Thus, it appears timely to investigate the possibility of using acute exercise as an adjuvant, especially in at-risk populations.

\section{References}

1. Havers F, Sokolow L, Shay DK, Farley MM, Monroe $\mathrm{M}$, Meek J, et al. Case-control study of vaccine effectiveness in preventing laboratory-confirmed influenza hospitalizations in older adults, United States, 2010-2011. Clin Infect Dis . 2016 Nov 15;63(10):1304-11. https://doi.org/10.1093/cid/ciw512

2. Mahase E. Covid-19: Moderna vaccine is nearly $95 \%$ effective, trial involving high risk and elderly people shows [Internet]. BMJ. 2020 Nov 17;371. https://doi.org/10 .1136/bmj.m4471

3. Knoll MD, Wonodi C. Oxford-AstraZeneca COVID19 vaccine efficacy. Lancet. 2021 Jan 9;397(10269):72-4. https://doi.org/10.1016/S01406736(20)32623-4

4. Keylock KT, Lowder T, Leifheit KA, Cook M, Mariani RA, Ross K, et al. Higher antibody, but not cell-mediated, responses to vaccination in high physically fit elderly. J Appl Physiol . 2007 Mar;102(3):1090-8. https://doi.org/10.1152/japplphysiol.00790.2006

5. Choon Lim Wong G, Narang V, Lu Y, Camous X, Nyunt MS, Carre C, et al. Hallmarks of improved immunological responses in the vaccination of more physically active elderly females [Internet]. Exerc Immunol Rev . 2019 Jan 1;25. Available from: http://www.eir-isei.de/2019/eir-2019-020-article.pdf

6. Ledo A, Schub D, Ziller C, Enders M, Stenger T, Gärtner BC, et al. Elite athletes on regular training show more pronounced induction of vaccine-specific T-cells and antibodies after tetravalent influenza vaccination than controls. Brain Behav Immun . 2020 Jan 1;83:135-45. https://doi.org/10.1016/j.bbi.2019.09.024 
7. de Araújo AL, Silva LC, Fernandes JR, Matias MD, Boas LS, Machado CM, et al. Elderly men with moderate and intense training lifestyle present sustained higher antibody responses to influenza vaccine. Age. 2015 Dec;37(6):1-8. https://doi.org/10.1007/s11357-015-9843-4

8. Edwards KM, Booy R. Effects of exercise on vaccineinduced immune responses. Hum Vaccin Immunother. 2013 Apr 1;9(4):907-10. https://doi.org/10.4161/hv.23365

9. Pascoe AR, Singh MA, Edwards KM. The effects of exercise on vaccination responses: a review of chronic and acute exercise interventions in humans. Brain Behav Immun . 2014 Jul 1;39:33-41. https://doi.org/10.1016/j.bbi.2013.10.003

10. Edwards KM, Burns VE, Reynolds T, Carroll D, Drayson M, Ring C. Acute stress exposure prior to influenza vaccination enhances antibody response in women. Brain Behav Immun . 2006 Mar 1;20(2):15968. https://doi.org/10.1016/j.bbi.2005.07.001

11. Edwards KM, Burns VE, Allen LM, McPhee JS, Bosch JA, Carroll D, et al.. Eccentric exercise as an adjuvant to influenza vaccination in humans. Brain Behav Immun. 2007 Feb 1;21(2):209-17. https://doi.org/10.1016/j.bbi.2006.04.158
12. Edwards KM, Burns VE, Adkins AE, Carroll D, Drayson M, Ring C. Meningococcal A vaccination response is enhanced by acute stress in men. Psychosom Med . 2008 Feb 1;70(2):147-51. http://doi.org/10.1097/PSY.0b013e318164232e

13. Edwards KM, Campbell JP. Acute exercise as an adjuvant to influenza vaccination. Am J Lifestyle Med $2011 \mathrm{Nov} ; 5(6): 512-7$. https://doi.org/10.1177\%2F1559827610395486

14. Bohn-Goldbaum E, Pascoe A, Singh MF, Singh N, Kok J, Dwyer DE, et al. Acute exercise decreases vaccine reactions following influenza vaccination among older adults. Brain Behav Immun Health . 2020 Jan 1;1:100009. https://doi.org/10.1016/j.bbih.2019.100009

15. Edwards KM, Pung MA, Tomfohr LM, Ziegler MG, Campbell JP, Drayson MT, et al. Acute exercise enhancement of pneumococcal vaccination response: a randomised controlled trial of weaker and stronger immune response. Vaccine. 2012 Oct 5;30(45):638995. https://doi.org/10.1016/j.vaccine.2012.08.022

16. Hull JH, Schwellnus MP, Pyne DB, Shah A. COVID19 vaccination in athletes: ready, set, go. Lancet Respir Med. 2021 May 1;9(5):455-6. https://doi.org/10.1016/S2213-2600(21)00082-5. https://doi.org/10.1016/j.ijinfomgt.2015.07.001

Peer Reviewed: Submitted 7 May 2021, accepted 29 May 2021, published 30 July 2021

Competing Interests: None declared.

Correspondence: Qais. Faculty of Medical Technology, Misurata, Libya. drqaiss9@gmail.com

Cite this article as: Gasibat Q. Exercising to enhance the efficacy of COVID-19 vaccines.

Christ J Global Health. July 2021; 8(1):

(C) Author. This is an open-access article distributed under the terms of the Creative Commons Attribution License, which permits unrestricted use, distribution, and reproduction in any medium, provided the original author and source are properly cited. To view a copy of the license, visit http://creativecommons.org/licenses/by/4.0/

\section{cjgh.org}

